\title{
Xenon preconditioning: molecular mechanisms and biological effects
}

\author{
Wenwu Liu ${ }^{1 \dagger}$, Ying Liu ${ }^{1,4+}$, Han Chen², Kan Liu' ${ }^{1}$ Hengyi Tao ${ }^{1,3}$ and Xuejun Sun ${ }^{1 *}$
}

\begin{abstract}
Xenon is one of noble gases and has been recognized as an anesthetic for more than 50 years. Xenon possesses many of the characteristics of an ideal anesthetic, but it is not widely applied in clinical practice mainly because of its high cost. In recent years, numerous studies have demonstrated that xenon as an anesthetic can exert neuroprotective and cardioprotective effects in different models. Moreover, xenon has been applied in the preconditioning, and the neuroprotective and cardioprotective effects of xenon preconditioning have been investigated in a lot of studies in which some mechanisms related to these protections are proposed. In this review, we summarized these mechanisms and the biological effects of xenon preconditioning.
\end{abstract}

Keywords: Xenon, Preconditioning, Neuroprotection, Cardioprotection, Mechanism

The noble gases are a group of chemical elements with very similar properties: they are all odorless, colorless, monatomic gases with very low chemical reactivity under standard conditions. The six noble gases occurring naturally are helium (He), neon $(\mathrm{Ne})$, argon (Ar), krypton $(\mathrm{Kr})$, xenon $(\mathrm{Xe})$, and the radioactive radon $(\mathrm{Rn})$ [1]. Among these noble gases, xenon is the most frequently investigated and widely applied in medicine. Xenon has been used as an anesthetic [2], to treat brain and heart injuries due to its neuroprotection and cardioprotection $[3,4]$ and in single photon emission computed tomography (SPECT) [5].

Preconditioning is a process by which an organism's exposure to a stress/stimulus permits it to decrease cellular damage or death when exposed to a subsequent greater or more sustained stress. To date, a large number of strategies have been developed for preconditioning such as lipopolysaccharide, heat and seizure, hypoxia and hyperoxia [6]. In this brief review, we introduce the protective effects of xenon preconditioning, not the xenon treatment.

\section{Introduction of xenon}

Xenon is a colorless, heavy, odorless noble gas and was discovered by William Ramsay and Morris Travers in

\footnotetext{
* Correspondence: sunxjk@hotmail.com

${ }^{\dagger}$ Equal contributors

${ }^{1}$ Department of Diving Medicine, Secondary Medical University, No 800

Xiangyin Road, Yangpu District, Shanghai 200433, People's Republic of China

Full list of author information is available at the end of the article
}

1898. Xenon derives its name from the Greek word for "stranger" [7]. Xenon is a trace gas in Earth's atmosphere and much more expensive than the lighter noble gases due to its very low concentration in air $(0.5 \mathrm{ppm})$ [2]. It is inert to most common chemical reactions because the outer valence shell contains eight electrons.

To date, xenon has been commercially used for lasers, high intensity lamps, flash bulbs, jet propellant in the aerospace industry, X-ray tubes, and in medicine [7].

In medicine, xenon has been used experimentally in clinical anesthetic practice for more than 50 years. As a general anesthetic, xenon possesses many advantages. For example, its blood-gas partition coefficient is extremely small (0.115), which results in a rapid onset and offset of its action. It lacks teratogenicity and can produce profound analgesia which thereby inhibits the surgery induced hemodynamic and catecholamine responses. It is also a potent hypnotic and does not produce hemodynamic depression because it at least in part has no influence on some important ion channels [2,7]. In addition, it has been confirmed that xenon can confer neuroprotective [3] and cardioprotective $[4,8]$ effects. Unlike nitrous oxide $\left(\mathrm{N}_{2} \mathrm{O}\right)$, xenon is not a greenhouse gas and so it is also viewed as environmentally friendly [9]. Xenon that is vented into the atmosphere is being returned to its original source, and thus environmental pollution is unlikely. However, its relatively high cost has precluded its more widespread clinical use.

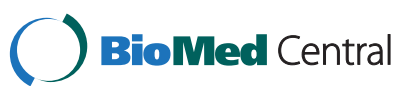




\section{Mechanisms underlying bioeffects of xenon}

Numerous studies have been conducted to investigate the mechanisms of xenon's bioeffects. Xenon can potently inhibit the N-methyl-D-aspartate (NMDA) receptors noncompetitively, with little effect on the $\gamma$-aminobutyric acid A $\left(\mathrm{GABA}_{\mathrm{A}}\right)$ receptor and non-NMDA glutamatergic receptor [10]. In the study of Yamakura and Harris, their results showed $\mathrm{N}_{2} \mathrm{O}(0.58$ atmosphere [atm]) and xenon (0.46 atm) exhibited similar effects on various receptors, and the NMDA receptors, and nACh receptors composed of $\beta 2$ subunits are likely targets for $\mathrm{NO}$ and xenon [11]. In addition, xenon (and NO) has been reported to competitively inhibit the 5-hydroxytryptamine receptor 3A (5HT3A receptor) expressed in the xenopus oocytes [12] but this has yet to be confirmed in mammalian cells.

In addition, the xenon induced anesthesia is related to the inhibition of the calcium ATPase pump on the cell membrane of synapses [13], which results from a conformational change when xenon binds to nonpolar sites inside the protein [14], and the non-specific interactions between the xenon and the lipid membrane [15].

\section{Mechanisms of protective effects of xenon preconditioning}

Cardioprotection, neuroprotection, renoprotective and endothelial protection

In 2005, a German group found that exposure to $70 \%$ xenon $45 \mathrm{~min}$ before myocardial ischemia could confer cardioprotection in a rat model, in which the activation of $\varepsilon$ isoform of protein kinase $\mathrm{C}$ and its downstream target p38 mitogen-activated protein kinase (MAPK) is a central molecular mechanism [16]. Eight months later, the same group preconditioned rats with same methods, but hearts without experiencing ischemia/reperfusion were collected for detection. Their results demonstrated that xenon preconditioning enhanced the translocation of heat shock protein 27 (HSP27) to the particulate fraction and increased F-actin polymerization and activated MAPKAPK-2 and HSP27 downstream of PKC and p38 MAPK. Moreover, F-actin and pHSP27 were colocalized after xenon preconditioning. Their findings link xenon preconditioning to the cytoskeleton, revealing new insights into the mechanisms of xenon preconditioning in vivo [17]. In another study of Weber et al., they found xenon preconditioning increased the translocation of $\mathrm{PKC}-\varepsilon$ to membrane regions, and the mitochondrial adenosine triphosphate (ATP) dependent potassium $\left(\mathrm{K}_{\mathrm{ATP}}\right)$ channels and $3^{\prime}$ phosphatidylinositol-dependent kinase-1 (PDK-1) located upstream of PKC- $\varepsilon$ and were crucial for the activation of PKC- $\varepsilon$ [18]. In addition, they noted ERK $1 / 2$, but not JNK, was also a mediator of xenon preconditioning [19]. A group in the USA found the cardioprotection of xenon preconditioning was attributed to the phosphorylation of Akt, glycogen synthase kinase $3 \beta$ (GSK-3 $\beta$ ), preservation of mitochondrial function, and inhibition of $\mathrm{Ca}^{2+}$-induced mitochondrial permeability transition (MPT) pore opening (Table 1) [20].

The neuroprotection of xenon preconditioning was attributed to the transcription of activity-dependent neuroprotective protein (ADNP) in neonatal rats [21], the opening of plasmalemmal $\mathrm{K}_{\mathrm{ATP}}$ channels in neuronalglial cocultures [22] and a reduction in the plasma IL-1 $\beta$ and an up-regulation of hippocampal HSP72 in the surgery and/or isoflurane induced postoperative cognitive decline (POCD) model [23]. Moreover, the neuroprotection of xenon preconditioning was independent of gender in mouse transient middle cerebral artery occlusion model [24].

In the study of $\mathrm{Ma}$ et al., the xenon preconditioning was found to be a natural inducer of hypoxia-inducible factor (HIF-1 $\alpha)[24,25]$. Xenon preconditioning can activate HIF- $1 \alpha$ and its downstream effectors erythropoietin (EPO) and vascular endothelial growth factor (VEGF) in a time-dependent manner in the kidneys in vivo and in vitro $[25,26]$.

In the human umbilical vein endothelial cells, xenon preconditioning was found to prevent tumor necrosis factor- $\alpha$ (TNF- $\alpha$ ) induced mRNA and protein expression of intracellular cell adhesion molecule 1 (ICAM-1) and vascular cell adhesion molecule 1 (VCAM-1) and decreased the TNF- $\alpha$ induced transcriptional activity of nuclear factor $\kappa \mathrm{B}(\mathrm{NF}-\mathrm{kB})$, but had no effect on the TNF- $\alpha$ induced E-selectin expression [27].

\section{Contribution of anesthetic property of xenon to protective effects}

Studies also revealed that preconditioning with other noble gases without anesthetic properties could exert protective effect $[28,29]$. These findings supported the contention that the protection of preconditioning with noble gases was independent of the anesthetic properties per se. However, the protective effect of preconditioning with other noble gases was not found in the human tubular kidney cells, and even helium by comparison significantly enhanced the cell injury [26]. Additionally, in a study of Baumert et al., they did not confirm the cardioprotective effect of brief, intermittent xenon preconditioning, but the xenon anesthesia (xenon $70 \%$, continued before and after myocardial ischemia) exert protective effect on myocardial ischemia [30]. Moreover, the xenon exposure induced gene expression profile was also found to be different from that following $\mathrm{N}_{2} \mathrm{O}$ (another anesthetic) exposure [31].

\section{Late protective effect of xenon preconditioning}

In previous studies, pharmacological preconditioning not only produces early protection but induces late 
Table 1 Mechanisms of protective effects of xenon preconditioning

\begin{tabular}{|c|c|}
\hline Mechanisms underlying protective effect of xenon preconditioning & Organ protection \\
\hline Activation of PKC- $\varepsilon$ isoform and p38 MAPK [16] & Cardioprotection \\
\hline HSP27 translocation, F-actin polymerization, activation of MAPKAPK-2, PKC and p38 MAPK [17] & Cardioprotection \\
\hline PKC- $\varepsilon$ translocation, mitochondrial ATP dependent $K_{\text {ATP }}$ channels, PDK-1 [18] & Cardioprotection \\
\hline ERK 1/2 [19] & Cardioprotection \\
\hline $\begin{array}{l}\text { Phosphorylation of Akt and GSK-3 } \beta \text {, preservation of mitochondrial function, and inhibition of } \\
\mathrm{Ca}^{2+} \text {-induced MPT pore opening [20] }\end{array}$ & Cardioprotection \\
\hline ADNP transcription [21] & Neuroprotection \\
\hline Opening of plasmalemmal $\mathrm{K}_{\text {ATP }}$ channels [22] & Neuroprotection \\
\hline Plasma IL-1 $\beta$ reduction and hippocampal HSP72 increase [23] & Neuroprotection \\
\hline HIF-1a, EPO and VEGF [24-26] & Renoprotection \\
\hline Reduction in ICAM-1, VCAM-1 and NF-KB [27] & $\begin{array}{l}\text { Protection on } \\
\text { endothelial cells }\end{array}$ \\
\hline COX-2 activity [32] & Cardioprotection \\
\hline $\begin{array}{l}\text { Enhanced phosphorylated cyclic adenosine monophosphate response element binding protein } \\
\text { signaling [33] }\end{array}$ & Neuroprotection \\
\hline pCREB-regulated synthesis of proteins [34] & Neuroprotection \\
\hline
\end{tabular}

protective effect. This was true in the xenon preconditioning [24,32-34]. The late myocardial protective effect of xenon preconditioning was found to be closely related to the cyclooxygenase-2 (COX-2) activity because inhibition of COX-2 abolished this cardioprotective effect and the mRNA and protein expression of COX-2 remained unchanged following xenon preconditioning [32], the enhanced phosphorylated cyclic adenosine monophosphate response element binding protein signaling [33] and the phosphorylated cAMP-response element binding protein (pCREB)-regulated synthesis of proteins that promote survival against neuronal injury (Table 1) $[33,34]$.

\section{Comparisons of xenon preconditioning with other strategies for preconditioning}

Investigators also compared the protective effects of xenon preconditioning with those of ischemia, anesthetic(s) and hypoxia preconditioning. In the experimental myocardial infarction model, results showed combined isoflurane/ xenon preconditioning reduced infarct size but not more than isoflurane alone. Ischemic preconditioning was more effective than the anesthetics [35]. In the rat $\mathrm{N}_{2} \mathrm{O}$ - and isoflurane-induced neuroapoptosis model, xenon preconditioning was found to prevent $\mathrm{N}_{2} \mathrm{O}$ oxide- and isofluraneinduced neuroapoptosis (in vivo and in vitro) and cognitive deterioration (in vivo). However, $\mathrm{N}_{2} \mathrm{O}$ - and isofluraneinduced neuroapoptosis was exacerbated by hypoxic pretreatment. $\mathrm{N}_{2} \mathrm{O}$ pretreatment had no effect [36]. In the study of Baumert et al., myocardial infarct size was reduced by ischemic preconditioning but less so by xenon anesthesia, and brief, intermittent exposure to xenon before myocardial ischemia did not reduce myocardial infarct size [30]. However, in the study of Weber et al., ischemic preconditioning induced by $3 \times 5$ min coronary artery occlusion reduced infarct size to a similar extent like anesthetic induced preconditioning [16].

\section{Conclusion and perspectives}

Although the anesthetic properties of xenon have been known for more than 50 years and the neuroprotection and cardioprotection of xenon demonstrated for more than 10 years, xenon preconditioning is still in its infant stage. The neuroprotective and cardioprotective effects of xenon preconditioning have been confirmed in the majority of studies, but clinical studies have not been reported. In addition, numerous signaling pathways and a large amount of molecules have been shown to involve in the protective effects of xenon preconditioning, but the relative contribution of each pathway or molecule is unclear to the protective effects of xenon preconditioning.

As shown above, the cost of xenon for anesthesia and treatment is high due to the large amount of xenon used, which is the major factor limiting the wide application of xenon. However, in the available experiments on xenon preconditioning, xenon was used in combination with oxygen at a ratio of 7:3 (v/v), and preconditioning was done with 3 cycles of xenon/oxygen administered for 5 min periods [20] or for up to $20 \mathrm{~min}$ [23]. If the protection of this strategy is confirmed, the cost of xenon may be significantly reduced as compared to that in the anesthesia and treatment. With the development of technology, closed-circuit xenon delivery is introduced. In the study of Chakkarapani et al., they reported that the xenon consumption was minimal $(<\$ 2 / \mathrm{h}$ at $\$ 10 /$ L) when the gas exchange was maintained [37]. Thus, 
xenon preconditioning is very cost-effective. Furthermore, xenon is not flammable and can be easily applied at bedside. Thus, we postulate that xenon preconditioning may become an alternative strategy for the prevention of diseases or injuries.

\section{Competing interests}

The authors declare that they have no competing interests.

\section{Authors' contributions}

Tao HY and Sun XJ outlined this review; Liu WW, Liu Y, Chen H and Liu K searched the database and summarized the findings; Liu WW and Liu Y drafted this manuscript; Tao HY and Sun XJ revised this review. All authors read and approved the final manuscript

\section{Acknowledgement}

This study was partially supported by the National Natural Science Foundation of China (No. 81000493/H0906).

\section{Author details}

Department of Diving Medicine, Secondary Medical University, No 800 Xiangyin Road, Yangpu District, Shanghai 200433, People's Republic of China. 2Department of General Surgery, 411 Hospital, No 15 Dongjiangwan Road, Hongkou District, Shanghai 200081, People's Republic of China. ${ }^{3}$ Institute of Nautical Medicine, Nantong University, Jiangsu 226019, People's Republic of China. ${ }^{4}$ Department of Pathology, Yantaishan Hospital, Yantai, Shandong 264000, People's Republic of China.

Received: 9 November 2012 Accepted: 25 December 2012 Published: 10 January 2013

\section{References}

1. Noble gas: http://en.wikipedia.org/wiki/Noble_gas.

2. Jordan BD, Wright EL: Xenon as an anesthetic agent. AANA J 2010, 78:387-392

3. Banks P, Franks NP, Dickinson R: Competitive inhibition at the glycine site of the $\mathrm{N}$-methyl-D-aspartate receptor mediates xenon neuroprotection against hypoxia-ischemia. Anesthesiology 2010, 112:614-622.

4. Pagel PS: Cardioprotection by noble gases. J Cardiothorac Vasc Anesth 2010, 24:143-163.

5. Suga K, Kawakami Y, Yamashita T, Zaki M, Matsunaga N: Characterization of ${ }^{133}$ Xe gas washout in pulmonary emphysema with dynamic ${ }^{133}$ Xe SPECT functional images. Nucl Med Commun 2006, 27:71-80.

6. Liu W, Khatibi N, Sridharan A, Zhang JH: Application of medical gases in the field of neurobiology. Med Gas Res 2011, 1:13.

7. Sanders R, Franks N, Maze M: Xenon: no stranger to anaesthesia. BrJ Anaesth 2003, 91:709-717.

8. Preckel B, Müllenheim J, Moloschavij A, Thämer V, Schlack W: Xenon administration during early reperfusion reduces infarct size after regional ischemia in the rabbit heart in vivo. Anesth Analg 2000, 91:1327-1332.

9. Goto T, Nakata Y, Morita S: Will xenon be a stranger or a friend? the cost benefit, and future of xenon anesthesia. Anesthesiology 2003, 98:1-2.

10. Franks NP, Dickinson R, de Sousa SL, Hall AC, Lieb WR: How does xenon produce anesthesia? Nature 1998, 396:324.

11. Yamakura T, Harris RA: Effects of gaseous anesthetics nitrous oxide and xenon on ligand-gated ion channels. Comparison with isoflurane and ethanol. Anesthesiology 2000, 93:1095-1101.

12. Suzuki T, Koyama H, Sugimoto M, Uchida I, Mashimo T: The diverse actions of volatile and gaseous anesthetics on human-cloned 5hydroxytryptamine 3 receptors expressed in Xenopus oocytes. Anesthesiology 2002, 96:699-704.

13. Franks JJ, Horn JL, Janicki PK, Singh G: Halothane, isoflurane, xenon, and nitrous oxide inhibit calcium ATPase pump activity in rat brain synaptic plasma membranes. Anesthesiology 1995, 82:108-117.

14. Lopez MM, Kosk-Kosicka D: How do volatile anesthetics inhibit $\mathrm{Ca}^{2+}$-ATPases? J Biol Chem 1995, 270(47):28239-28245.

15. $X u$ Y, Tang P: Amphiphilic sites for general anesthetic action? Evidence from ${ }^{129} \mathrm{Xe}-\left[{ }^{1} \mathrm{H}\right]$ intermolecular nuclear Overhauser effects. Biochim Biophys Acta 1997, 1323(1):154-162
16. Weber NC, Toma O, Wolter JI, Obal D, Müllenheim J, Preckel B, Schlack W: The noble gas xenon induces pharmacological preconditioning in the rat heart in vivo via induction of PKC-epsilon and p38 MAPK. BrJ Pharmacol 2005, 144:123-132.

17. Weber NC, Toma O, Wolter Jl, Wirthle NM, Schlack W, Preckel B: Mechanisms of xenon- and isoflurane-induced preconditioning - a potential link to the cytoskeleton via the MAPKAPK-2/HSP27 pathway. Br J Pharmacol 2005, 146:445-455.

18. Weber NC, Toma O, Damla H, Wolter JI, Schlack W, Preckel B: Upstream signaling of protein kinase $\mathrm{C}$-epsilon in xenon-induced pharmacological preconditioning. Implication of mitochondrial adenosine triphosphate dependent potassium channels and phosphatidylinositol dependent kinase-1. Eur J Pharmacol 2006, 539:1-9.

19. Weber NC, Stursberg J, Wirthle NM, Toma O, Schlack W, Preckel B: Xenon preconditioning differently regulates p44/42 MAPK (ERK 1/2) and p46/54 MAPK (JNK 1/2 and 3) in vivo. Br J Anaesth 2006, 97:298-306.

20. Mio Y, Shim YH, Richards E, Bosnjak ZJ, Pagel PS, Bienengraeber M: Xenon preconditioning: the role of prosurvival signaling, mitochondrial permeability transition and bioenergetics in rats. Anesth Analg 2009, 108:858-866.

21. Cattano D, Valleggi S, Ma D, Kastsiuchenka O, Abramo A, Sun P, Cavazzana $A O$, Natale $G$, Maze $M$, Giunta F: Xenon induces transcription of ADNP in neonatal rat brain. Neurosci Lett 2008, 440:217-221.

22. Bantel C, Maze M, Trapp S: Neuronal preconditioning by inhalational anesthetics: evidence for the role of plasmalemmal adenosine triphosphate-sensitive potassium channels. Anesthesiology 2009, 110:986-995.

23. Vizcaychipi MP, Lloyd DG, Wan Y, Palazzo MG, Maze M, Ma D: Xenon pretreatment may prevent early memory decline after isoflurane anesthesia and surgery in mice. PLoS One 2011, 6:e26394.

24. Limatola V, Ward P, Cattano D, Gu J, Giunta F, Maze M, Ma D: Xenon preconditioning confers neuroprotection regardless of gender in a mouse model of transient middle cerebral artery occlusion. Neuroscience 2010, 165:874-881.

25. Ma D, Lim T, Xu J, Tang H, Wan Y, Zhao H, Hossain M, Maxwell PH, Maze M: Xenon preconditioning protects against renal ischemic-reperfusion injury via HIF-1alpha activation. J Am Soc Nephrol 2009, 20:713-720.

26. Rizvi M, Jawad N, Li Y, Vizcaychipi MP, Maze M, Ma D: Effect of noble gases on oxygen and glucose deprived injury in human tubular kidney cells. Exp Biol Med (Maywood) 2010, 235:886-891.

27. Weber NC, Kandler J, Schlack W, Grueber Y, Frädorf J, Preckel B: Intermitted pharmacologic pretreatment by xenon, isoflurane, nitrous oxide, and the opioid morphine prevents tumor necrosis factor alpha-induced adhesion molecule expression in human umbilical vein endothelial cells. Anesthesiology 2008, 108:199-207.

28. Pagel PS, Krolikowski JG, Shim YH, Venkatapuram S, Kersten JR, Weihrauch D, Warltier DC, Pratt PF Jr: Noble gases without anesthetic properties protect myocardium against infarction by activating prosurvival signaling kinases and inhibiting mitochondrial permeability transition in vivo. Anesth Analg 2007, 105:562-569.

29. Pagel PS, Krolikowski JG, Pratt PF Jr, Shim YH, Amour J, Warltier DC, Weihrauch D: The mechanism of helium-induced preconditioning: a direct role for nitric oxide in rabbits. Anesth Analg 2008, 107:762-768.

30. Baumert JH, Hein M, Gerets C, Baltus T, Hecker KE, Rossaint R: The effect of xenon anesthesia on the size of experimental myocardial infarction. Anesth Analg 2007, 105:1200-1206.

31. Valleggi S, Cavazzana AO, Bernardi R, Ma D, Natale G, Maze M, Cattano D, Giunta F: Xenon up-regulates several genes that are not up-regulated by nitrous oxide. J Neurosurg Anesthesiol 2008, 20:226-232.

32. Weber NC, Frässdorf J, Ratajczak C, Grueber Y, Schlack W, Hollmann MW, Preckel $B:$ Xenon induces late cardiac preconditioning in vivo: a role for cyclooxygenase 2? Anesth Analg 2008, 107:1807-1813.

33. Luo Y, Ma D, leong E, Sanders RD, Yu B, Hossain M, Maze M: Xenon and sevoflurane protect against brain injury in a neonatal asphyxia model. Anesthesiology 2008, 109:782-789.

34. Ma D, Hossain M, Pettet GK, Luo Y, Lim T, Akimov S, Sanders RD, Franks NP, Maze $\mathrm{M}$ : Xenon preconditioning reduces brain damage from neonatal asphyxia in rats. J Cereb Blood Flow Metab 2006, 26:199-208.

35. Baumert JH, Hein M, Gerets C, Baltus T, Hecker KE, Rossaint R: The effect of xenon on isoflurane protection against experimental myocardial infarction. J Cardiothorac Vasc Anesth 2009, 23:614-618. 
36. Shu Y, Patel SM, Pac-Soo C, Fidalgo AR, Wan Y, Maze M, Ma D: Xenon pretreatment attenuates anesthetic-induced apoptosis in the developing brain in comparison with nitrous oxide and hypoxia. Anesthesiology 2010, 113:360-368.

37. Chakkarapani E, Thoresen M, Hobbs CE, Aquilina K, Liu X, Dingley J: A closed-circuit neonatal xenon delivery system: a technical and practical neuroprotection feasibility study in newborn pigs. Anesth Analg 2009, 109:451-460.

doi:10.1186/2045-9912-3-3

Cite this article as: Liu et al:: Xenon preconditioning: molecular mechanisms and biological effects. Medical Gas Research 2013 3:3.

\section{Submit your next manuscript to BioMed Central and take full advantage of:}

- Convenient online submission

- Thorough peer review

- No space constraints or color figure charges

- Immediate publication on acceptance

- Inclusion in PubMed, CAS, Scopus and Google Scholar

- Research which is freely available for redistribution 